\section{Prevalence of self-reported chronic diseases in individuals over the age of 40 in São Paulo, Brazil: the PLATINO Study}

\author{
Prevalência de doenças crônicas autorrelatadas em \\ indivíduos acima de 40 anos em São Paulo, Brasil: \\ Estudo PLATINO
}

\author{
1 Universidade Federal de São \\ Paulo, São Paulo, Brasil. \\ 2 Lar Escola São Francisco, \\ São Paulo, Brasil. \\ 3 Faculdade de Medicina, \\ Universidade Federal de \\ Pelotas, Pelotas, Brasil. \\ 4 Instituto Nacional de \\ Enfermedades Respiratorias, \\ México DF, México. \\ Correspondence \\ J. R. Jardim \\ Universidade Federal de São \\ Paulo. \\ Rua Botucatu 740, 3o andar, \\ São Paulo, SP 04023-062, \\ Brasil. \\ jardimpneumo@gmail.com
}

\section{Abstract}

Few studies have been conducted to determine the prevalence of chronic diseases and its impact in individuals aged 40 years or over in Brazil. The objective of this study is to evaluate the prevalence of some common chronic diseases in the Brazilian subgroup assessed by the PLATINO study using a self-reported survey. A total of 918 individuals (55\% women) with a mean age of $54.6 \pm 10.9$ years were evaluated. The most prevalent diseases were obesity (62.5\%), hypertension (39.2\%) and gastritis (30.9\%). We conclude from this study that there is a high prevalence of chronic diseases in the population over 40 years of age: $88 \%$ of the population suffers from a minimum of one disease and $26 \%$ of the sample suffers from at least three diseases. We also observed that the number of comorbidities increases with age.

Chronic Disease; Comorbidity; Health Promotion

\author{
Andréa K. Carvalho 1,2 \\ Ana Maria B. Menezes 2,3 \\ Aquiles Camelier 1,2 \\ Fernanda Warken Rosa 1,2 \\ Oliver A. Nascimento 1,2 \\ Rogelio Perez-Padilla 2,4 \\ José R. Jardim 1,2
}

\section{Introduction}

Public health programs are generally designed according to the prevalence of the diseases they are targeted at. In Brazil, a national survey (PNAD - Brazilian National Household Sampling Survey) carried out over the last 42 years by the central government has been used as an important source of information for developing public health service guidelines 1 . Other surveys that focus on specific groups have also been carried out and provide interesting information that has been used by the public health authorities. One such study is the EPIDOSO Survey that has followed up an ageing population 2 in São Paulo over the last two decades evaluating the most prevalent diseases in the individuals studied.

However, this study presents a selection bias since the sample, taken from only two areas nearby the University, is not representative of the population of São Paulo ${ }^{2}$. As this population was not randomized it is possible that the samples are strongly subject to chance: the population of the study comprised only groups of individuals who were already sick or healthy individuals, both of which were seeking quality health care. With respect to the 2003 PNAD Survey 1, 70\% of the sample population was under 40 years of age, not reflecting the real demographic situation in Brazil [Brazilian Institute of Geography and Statistics (Instituto Brasileiro de Geografia e Estatística - IBGE)]. In addition, the survey did 
not evaluate two very common clinical situations in Brazil: chronic obstructive pulmonary disease and obesity.

Population based sampling is the ideal method to evaluate the actual prevalence of a disease and assess the level of access a given population has to public health care $1,2,3$. With respect to disease prevalence, a strong correlation has already been shown between self-diagnosis and diagnosis based on clinical evaluation 4 .

The Latin American Project for the Investigation of Obstructive Lung Disease (PLATINO) aimed to determine the prevalence of chronic obstructive pulmonary disease and associated risk factors in five major metropolitan areas in Latin America: São Paulo (Brazil), Santiago (Chile), Mexico City (Mexico), Montevideo (Uruguay) and Caracas (Venezuela). The study consisted of a randomized household survey that used a questionnaire to collect data on the prevalence of chronic obstructive pulmonary disease, as well as the demographic, spirometry and general characteristics of the population. In the case of Brazil, the questionnaire included questions about prevalent diseases among the sample population 3. In São Paulo, the study found a high prevalence of chronic obstructive pulmonary disease $(15.8 \%)^{3}$ and over $60 \%$ of the sample population was shown to be overweight or obese 5 . Obesity is strongly associated with cardiovascular diseases, diabetes and metabolic syndrome, diseases that usually impose a high burden on the health care system.

Despite the methodological quality of the EPIDOSO and PNAD studies, neither evaluated lung function or individuals' body mass index by measuring the height and weight of individuals at their homes. A definitive diagnosis of chronic obstructive pulmonary disease can only be made using spirometry.

Other diseases with high morbidity and mortality that impose a high burden on the health care system were also evaluated by the PLATINO study. Information regarding prevalence of asthma, tuberculosis, heart disease, systemic arterial hypertension, diabetes, lung cancer, stroke, gastritis and ulcers were collected using a selfreported method.

This study consists of a subanalysis of the PLATINO study and aimed to evaluate the selfreported prevalence of certain highly prevalent chronic diseases in Brazil combining the objective measurement of lung function, weight and height in a cluster analysis of a survey sample in the city of São Paulo.

\section{Material and methods}

\section{Study design}

The study was approved by the Ethics and Research Committee of the São Paulo Federal University (Universidade Federal de São Paulo UNIFESP), Brazil, and was based on data collected by the PLATINO study. The methods and results regarding chronic obstructive pulmonary disease prevalence in Latin America have been published in previous studies 3,5 . Briefly, PLATINO was a transversal study designed to determine chronic obstructive pulmonary disease prevalence and associated risk factors in five large metropolitan areas of Latin America, including São Paulo in Brazil. The study sample was selected using clusters in several stages. Firstly, the metropolitan area was stratified into main city and surrounding municipalities. These two subsets were then further stratified by socioeconomic status. Based on these stratifications we selected 68 census tracts using a probability of selection proportionate to the number of households in each tract. Within each tract, we counted the number of individuals in each household and every count was updated based on the most recent census. We chose an average of 15 households using systematic sampling within each tract. All adults aged 40 years or over living in selected households were invited to participate and those who accepted signed a consent form and were submitted to the evaluations in their home.

\section{Questionnaire and evaluations}

All interviews and examinations took place in the subject's home, and proxy information was not accepted. We obtained data regarding respiratory health using a standardized questionnaire which included sections from the American Thoracic Society Division of Lung Diseases (ATS/DLD) 6, European Community Respiratory Health Survey II 7 and Lung Health Study instruments 8 . This questionnaire has been used to investigate respiratory diseases and symptoms 3,9 in a number of countries, including Brazil 5. Questions related to the presence of respiratory symptoms, self-diagnosis of other chronic diseases, such as asthma, heart disease, systemic arterial hypertension, diabetes, lung cancer, stroke and gastritis or ulcers. The following question was asked: "Has a doctor ever told you that you have heart disease?". The same question was asked regarding "high blood pressure" ("hipertensão"), "blood sugar” or “diabetes”, “lung cancer", "stroke" or "cerebral ischemia" ("derrame”), "lung tuberculosis”, “asthma”, "gastritis or ulcer”. 
The questionnaire also assessed the number of completed school years of each subject and smoking history. Height was measured with a portable stadiometer (Seca, Curitiba, Brazil; precision $0.1 \mathrm{~cm}$ ) and subjects were weighed with an electronic scale (Tanita; Curitiba, Brazil; precision 200g) to calculate their body mass index (BMI) Individuals with a BMI of over $25 \mathrm{~kg} / \mathrm{m}^{2}$ were defined as overweight and those with a BMI of over $30 \mathrm{~kg} / \mathrm{m}^{2}$ were considered obese 10 . In addition, pre and post-bronchodilator spirometry was performed (Easy-One; NDD Medical Technologies, Chelmsford, USA, and Zurich, Switzerland) and chronic obstructive pulmonary disease was diagnosed where the post-bronchodilator FEV1/FVC was less than $0.711,12,13$. If subjects answered "yes" to any of the questions related to history of previous disease and/or presented a BMI of over $25 \mathrm{~kg} / \mathrm{m}^{2}$ and/or a FEV1/FVC ratio lower than 0.70 (chronic obstructive pulmonary disease), the data was evaluated to determine the prevalence of each disease. In addition, the number of diseases presented by each subject was verified and stratified/classified as 1-2, 3-4 or over 5 diseases.

The sample size of this study was determined based on the prevalence of chronic obstructive pulmonary disease. Sample size calculations suggested that 800 individuals would be needed to estimate a prevalence of chronic obstructive pulmonary disease of up to $30 \%$ with a margin of error of less than 4 percent. We aimed to locate about 1,020 eligible participants per site, with a predicted $20 \%$ refusal rate. The initial sample looked at chronic obstructive pulmonary disease prevalence. Only $12 \%$ of this sample was defined as "not having a self-reported disease". Based on these results and assuming a total amplitude confidence interval of 0.10 and a confidence interval of $99 \%$, it was calculated that it would be necessary to evaluate a total of 339 subjects 14 .

\section{Statistical analysis}

Continuous variables are presented as mean \pm standard deviation. The categorical variables are expressed as number of subjects and percentage. The chi-square test was used to test the association between qualitative variables. The Student's t-test was used to compare the mean of two groups. Statistical analysis was performed utilizing Stata 8.0 (Stata Corp., College Station, USA) and SPSS 10.0 (SPSS Inc., Chicago, USA).

The prevalence of each disease or combination of diseases was calculated for the whole sample. In addition, to evaluate and compare the prevalence and number of concomitant diseases, age was stratified into various groups: 40 to 49 years, 50 to 59 years, 60 to 69 years and over 70 years.

The type I error rate was maintained at $5 \%$.

\section{Results}

A total of 1,000 subjects completed the questionnaire and 918 performed pre and post-bronchodilator spirometry test. The level of non-response was $15.3 \%$, including failure to locate the residence or individual and refusal to take the spirometric test. The age and smoking history characteristics of non-responders and responders were similar.

The demographic data is shown in Table 1. The age of the sample population ranged predominantly between 40 and 60 years $(72.7 \%)$ with a mean of $54.6 \pm 10.9$ years. The sample was predominantly female and white. The subjects had completed an average of six years of schooling. The sample comprised predominantly nonsmokers (42.2\%), 32.9\% ex-smokers and $24.9 \%$ current smokers. The mean smoking load was 18 packs per year.

The prevalence of the diseases studied is shown in Figure 1. The number of diseases tend-

Table 1

Demographic and clinical characteristics of the study population $(n=918)$.

\begin{tabular}{lc}
\hline Variable & Value \\
\hline Age (years \pm ) & $54.6(10.9)$ \\
Age stratified (years) [n (\%)] & \\
$40-49$ & $372(40.5)$ \\
$50-59$ & $296(32.2)$ \\
$60-69$ & $151(16.9)$ \\
70 and older & $99(10.8)$ \\
Gender [n (\%)] & \\
Male & $413(45)$ \\
Female & $505(55)$ \\
Race [n (\%)] & \\
White & $528(57.5)$ \\
Non white & $390(42.5)$ \\
Education (years \pm ) & $6.0(4.8)$ \\
BMI [kg/m² \pm SD] & $27.3(5.5)$ \\
Smoking History [pack-years \pm$]$ & $18.0(22.8)$ \\
Smoking status [n (\%)] & \\
Non smoker & $387(42.2)$ \\
Ex-smoker & $302(32.9)$ \\
Smoker & $229(24.9)$ \\
\hline
\end{tabular}

BMI: body mass index; SD: standard deviation. 
ed to increase with age. The most common comorbidity was obesity, followed by systemic arterial hypertension. The prevalence of obesity was high in all age groups. We also found a low incidence of lung cancer and stroke for all age groups (Figure 1).

Comorbidity was associated with age (see Table 2). The number of diseases in the population increased with age, from 1.6 diseases per person in the 40 to 49 years age group to 2.3 diseases per person in the 70 years and over age group (see Table 2; $\mathrm{p}<0.001$ ).

\section{Discussion}

This study is a subanalysis of the PLATINO study, which was designed to evaluate the prevalence of chronic obstructive pulmonary disease in Latin America. In our study, the data analysis is restricted to the adult population of São Paulo aged 40 years and over, a commonly used sample type in epidemiological studies regarding chronic obstructive pulmonary disease.

Our subanalysis concerned the prevalence of ten diseases in the metropolitan area of São Paulo using a self-reported questionnaire and objective measurements of lung function and BMI ${ }^{3}$. The questionnaire was adapted from standardized and validated questionnaires 6,7 which are widely used in other respiratory epidemiological studies in Europe and Asia ${ }^{9}$.

Other surveys undertaken in Brazil and other countries have evaluated large samples focusing on specific diseases 15,16,17. However, few studies have analyzed the characteristics of the surveyed individuals associated with these diseases. Knowledge of factors associated with these diseases would help to develop a multidimensional approach which could be more cost effective for the health care system.

Ramos et al. 2 conducted a prevalence study of an ageing population, including individuals over 65 years of age, in a district of the city of São Paulo and found that only $5.6 \%$ of the sample did not present any chronic disease and reported a strong association between diseases. However their study was not randomized, was restricted to one district of São Paulo and only comprised older individuals. Despite these flaws, the very low percentage of individuals without any chronic disease is very similar to the findings in our subset group aged 60 years and over (6.8\%).

An important finding was made regarding the number of diseases per individual and age: at least $88 \%$ of the present study population had

Figure 1

Prevalence of diseases by age group.

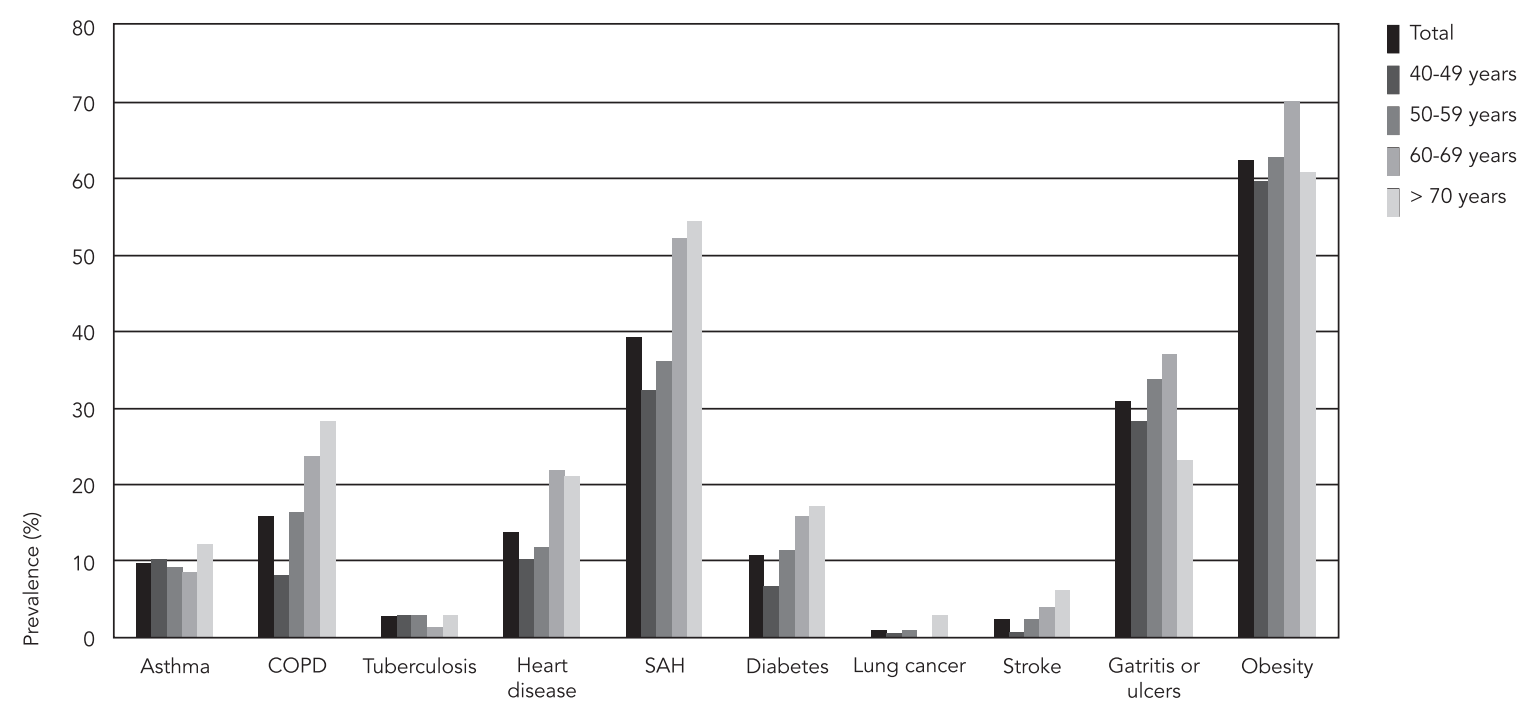

COPD: chronic obstructive pulmonary disease; $\mathrm{SAH}$ : systemic arterial hypertension.

${ }^{*} p<0.05$. Chi-square test. 
Number of diseases by age group.

\begin{tabular}{|c|c|c|c|c|c|c|c|c|}
\hline \multirow{2}{*}{$\begin{array}{l}\text { Number } \\
\text { of chronic } \\
\text { diseases * }\end{array}$} & \multicolumn{2}{|c|}{$40-49$ years } & \multicolumn{2}{|c|}{$50-59$ years } & \multicolumn{2}{|c|}{$60-69$ years } & \multicolumn{2}{|c|}{ Over 70 years } \\
\hline & $n(\%)$ & $95 \% \mathrm{Cl}$ & n (\%) & $95 \% \mathrm{Cl}$ & n (\%) & $95 \% \mathrm{Cl}$ & n (\%) & $95 \% \mathrm{Cl}$ \\
\hline None & $63(16.9)$ & $13.1-20.7$ & $30(10.2)$ & $6.8-13.6$ & $11(7.3)$ & $3.2-11.4$ & $6(6.1)$ & $1.4-10.8$ \\
\hline $1-2$ & $237(63.7)$ & $58.8-68.6$ & $184(62.4)$ & $56.9-67.9$ & $70(46.4)$ & $38.4-54.4$ & $58(58.6)$ & $48.9-68.3$ \\
\hline $3-4$ & $68(18.3)$ & $14.4-22.2$ & $72(24.4)$ & $19.5-29.3$ & $62(41.1)$ & $33.3-48.9$ & $28(28.3)$ & $19.4-37.2$ \\
\hline$>5$ & $4(1.1)$ & $0.0-2.2$ & $9(3.1)$ & $1.1-5.1$ & $8(5.3)$ & $1.7-8.9$ & $7(7.1)$ & $2.0-12.2$ \\
\hline
\end{tabular}

95\% $\mathrm{Cl}$ : 95\% confidence interval.

${ }^{\star} p<0.001$. Chi-square test.

one or two diseases, $60 \%$ of the individuals, irrespective of the age group, had one or two diseases and the percentage of individuals with three or more diseases tended to increase with age (Table 2). Concomitant diseases require comprehensive treatment with a multidisciplinary approach and can result in potential medication interactions.

We found a high prevalence of individuals who were overweight and obese (BMI $\geq 25 \mathrm{~kg}$ / $\mathrm{m}^{2}$ ). Monteiro et al. 18 found a $39 \%$ prevalence of overweight and obese individuals among the Brazilian population, which is a significant contrast to the findings of this study (62\%). This difference may be due to the age group of the PLATINO study which included only individuals aged 40 years or over, known to have lower metabolic activity and a greater tendency to gain weight. Recent surveys in Brazil have shown that the population tends to be overweight 19. Based on data from the NHANES III study in 1999, the prevalence of excess weight and obesity in individuals in the United States aged 25 years or over was $63 \%$ for men and $55 \%$ for women (BMI $\geq$ $\left.25 \mathrm{~kg} / \mathrm{m}^{2}\right)^{3}$, which is similar to the findings of this study. Barros et al. 20 studied the social disparities related to the prevalence of chronic diseases in Brazil and found lower prevalence for individuals of the same age group covered by our study. Obesity is an important contributor to the development of other comorbidities such as diabetes, systemic arterial hypertension and cardiovascular diseases. Combating this problem in health programs requires a multifaceted approach including knowledge regarding nutrition, exercise and metabolism 20.

Population surveys carried out in Brazilian cities over the past 20 years have shown a prevalence of over $30 \%$ of systemic arterial hypertension in the Brazilian population 21,22, which is similar to the findings of this study: $32.3 \%$ for the 40 to 49 years age group and $36.1 \%$ for the 50 to
59 years age group. Findings regarding disease prevalence in individuals in the city of São Paulo relating to the period 2001 to 2002 published by Coutinho et al. 23 were comparable to our study for the 40 to 49 years age group (36\%) but higher in the case of the 50 to 59 years age group (53\%). The other age groups evaluated by the present study were not examined by Coutinho et al. 23 . These figures are particularly important considering that this population is more prone to cerebrovascular accidents and developing ischemic cardiovascular diseases and peripheral arterial insufficiency 24 .

Gastritis and ulcers were ranked as the third most common disorder in our sample. However it should be noted that self-diagnosis of these diseases is difficult because their symptoms may be confused with other dyspeptic symptoms 25,26. We are not aware of any Brazilian data related to the prevalence of gastritis or ulcers. In 2002, based on a study of gastric biopsies, Coelho at al. 27 showed that the estimated prevalence of infection by $H$. pylori in Latin America was $60 \%$, with a wide range of variation from $30 \%$ to $90 \%$. The prevalence rates found by the present study for gastritis (28\%) and ulcers (36\%) were below the mean value reported by Coelho at al. 27 but within the range cited by these authors. In Brazil, a population-based study 28 indicated a prevalence rate of $44 \%$ for dyspeptic syndrome. Although this syndrome was highly prevalent in the general population, only $25 \%$ of individuals seek medical treatment for this illness. It is therefore possible that the number of individuals who reported gastritis or ulcers in our study could be an underestimate.

Self-reported heart disease in our study ranks fourth in the list of disease prevalence and shows an increasing trend with age, reaching $21.2 \%$ in the 70 years and over age group. The term heart disease can encompass various illnesses such as 
arrhythmia, myocardiopathy, aortic valve disease and coronary disease (angina). However, the questionnaire used in this study was not designed to carry out an individual evaluation of such diseases. As heart disease is the leading cause of mortality in Brazil, this was already an expected finding in our study.

The incidence of chronic obstructive pulmonary disease increased with age. The prevalence of this disease in São Paulo, which may affect as many as seven million people in Brazil, was $15.8 \%$ in individuals aged 40 years and over 3,5 . It is well known that chronic obstructive pulmonary disease imposes a substantial burden on the Brazilian Unified National Health System (SUS): approximately 180,000 patients per year are admitted to hospital due to this disease and it was the sixth greatest cause of death in Brazil in 2004, with 33,000 deaths (Health Information Department. http://www.datasus. gov.br, accessed on 12/Oct/2011). Despite the high burden on public health, chronic obstructive pulmonary disease is under diagnosed and undertreated 29.

According to the Brazilian Survey on Diabetes (1992) carried out by Franco et al. 30, this disease was shown to have an age-adjusted prevalence (30 to 69 years) of $7.6 \%$, with a variation of $5 \%$ to $10 \%$, in the different state capitals evaluated $(6.7 \%)$. However, rates in the present study were as high as $17.2 \%$ in the 70 years or over age group. The increase in prevalence of diabetes in the two age groups - 60 to 69 years and 70 years or over - may be associated with several factors, including the fact that as a person ages the number of insulin receptors decreases and the blood glucose levels rise 31 .

An important observation of our study is that the mean number of diseases per person increased with age. This increasing trend in the association between chronic comorbidities may be due to the chronic character of these diseases, associated with the fact that, despite being treatable, they are not curable.

One possible limitation of this study is that the prevalence of diseases was based on the PLATINO questionnaire that concerns only certain specific diseases. However, it is important to highlight that, although the primary objective of the PLATINO study was not the same as that of the present analysis, the rigorous study design and very good quality control acts as an assurance of reliable data. Several other studies have also used surveys or questionnaires to identify the prevalence of diseases and show health care utilization 32,33 . It is also important to note that the information obtained from the PLATINO study has not been previously revealed.

We can make the following conclusions from this study: there is a high prevalence of chronic diseases in the Brazilian population aged 40 years or over; $88 \%$ of the population suffers from at least one disease and $26 \%$ of the individuals of our sample had at least three diseases. We also observed that the number of comorbidities increases with age. 


\section{Resumo}

Poucos estudos foram desenvolvidos para determinar a prevalência de doenças crônicas e suas associações em indivíduos com mais de 40 anos de idade no Brasil. O objetivo deste trabalho foi avaliar a prevalência de algumas doenças crônicas altamente prevalentes no país, de modo autorreferido, avaliadas no Estudo PLATINO em São Paulo, em uma amostra de base populacional. Novecentos e dezoito indivíduos (55\% mulheres) com média de idade de 54,6 \pm 10,9 anos foram avaliados. As três doenças mais prevalentes foram obesidade (62,5\%), hipertensão (39,2\%) e gastrite (30,9\%). Há uma alta prevalência de doenças crônicas na população acima de 40 anos: $88 \%$ da amostra apresentaram pelo menos uma doença e $26 \%$, pelo menos, três doenças; e o número de doenças apresentava tendência a aumentar com a idade.

Doença Crônica; Comorbidade; Promoção da Saúde

\section{Contributors}

A. K. Carvalho, O. A. Nascimento and J. R. Jardim made a substantial contribution to study conception and design, data collection, analysis and interpretation and in drafting this article, critical content revision and approval of the final version. A. M. B. Menezes, A. Camelier, F. W. Rosa and R. Perez-Padilla made a substantial contribution to study conception and design, data collection, analysis and interpretation.

\section{Acknowledgments}

A. K. Carvalho and F.W. Rosa received scholarships from CAPES. The PLATINO study was funded by Boehringer Ingelheim GmbH. We are also grateful to Dra. C. N. Aguiar for her help with the translation and editing of the manuscript.

\section{References}

1. Instituto Brasileiro de Geografia e Estatística. Pesquisa Nacional por Amostra de Domicílios - PNAD-2003. http://www.ibge.gov.br/home/ estatistica/populacao/trabalhoerendimento/ pnad2003/sintesepnad2003.pdf (accessed on 11/ Oct/2011).

2. Ramos LR, Toniolo J, Cendoroglo MS, Garcia JT, Najas MS, Perrecini M, et al. Two year follow-up study of elderly residents in S. Paulo, Brazil: methodology and preliminary results. Rev Saúde Pública 1998; 32:397-407.

3. Menezes AMB, Padilla RP, Jardim JR, Muino A, Lopez MV, Valdivia G. Chronic obstructive pulmonary disease in five latin american cities (the PLATINO study): a prevalence study. Lancet 2005; 366:1875-81.

4. Viacava F. Informações em saúde: a importância dos inquéritos populacionais. Cienc Saúde Coletiva $2002 ; 7: 607-21$.

5. Menezes AMB, Jardim JR, Padilla RP, Camelier A, Rosa F, Nascimento O, et al. Prevalence of chronic obstructive pulmonary disease and associated factors: the PLATINO Study in São Paulo, Brazil. Cad Saúde Pública 2005; 21:1565-73.
6. Ferris BG. Epidemiology standardization project (American Thoracic Society). Am Rev Respir Dis 1978; 118(6 Pt 2):1-120.

7. European Community Respiratory Health Survey II Steering Committee. The European Community Respiratory Health Survey II. Eur Respir J 2002; 20:1071-9.

8. BC Cancer Research Centre. BC Cancer Research Centre Lung Health Study Questionnaire. Vancouver: BC Cancer Research Centre; 2004.

9. Buist SA, McBurnie MA, Vollmer WM, Gillespie S, Burney P, Mannino DM, et al. International variation in the prevalence of COPD (The BOLD Study): a population-based prevalence study. Lancet 2007; 370:741-50.

10. World Health Organization. Physical status: the use and Interpretation of anthropometry. Report of WHO expert committee. Geneva: World Health Organization; 1995. (WHO Technical Report Series, 854).

11. II Consenso Brasileiro sobre Doença Pulmonar Obstrutiva Crônica (DPOC). J Bras Pneumol 2004; 30 Suppl 5:S1-42. 
12. Celli Br, MacNee W. Standards for the diagnosis and treatment of patients With COPD: a summsry of the ATS/ERS position paper. Eur Respir J 2004; 23:932-46.

13. Rabe F, Hurd S, Anzueto A, Barnes PJ, Buist SA, Calverley P, et al. Global strategy for the diagnosis, management, and prevention of chronic obstructive pulmonary disease: GOLD executive summary. Am J Respir Crit Care Med 2007; 176:532-55.

14. Hulley SB, Commings SR, Browner WS, Grady D, Hearst N, Newman TB. Designing clinical research: an epidemiologic approach. $2^{\text {nd }}$ Ed. Philadelphia: Lippincott Williams \& Wilkins; 2001.

15. Mannino DM, Gagnon RC, Petty TL, Lydick E. Obstructive lung disease and low lung function in adults in the United States: data from the National Health and Nutrition Examination Survey, 19881994. Arch Intern Med 2000; 160:1683-9.

16. Peña VS, Miravitles M, Gabriel R, Jimenez-Ruiz CA, Villasante C, Masa JF. Geographic variations in prevalence and underdiagnosis of COPD: results of the IBERPOC Multicentre Epidemiological Study. Chest 2000; 118:981-9.

17. Vestbo J, Prescott E, Lange P. Association of chronic mucus hypersecretion with FEV1 decline and chronic obstructive pulmonary disease morbidity. Copenhagen City Heart Study Group. Am J Respir Crit Care Med 1996; 1530-5.

18. Monteiro CA, Conde WL. Tendência secular da obesidade segundo estratos sociais: Nordeste e Sudeste do Brasil 1975-1989-1997. Arq Bras Endocrinol Metab 1999; 43:186-94.

19. Instituto Brasileiro de Geografia e Estatística. Pesquisa Nacional por Amostra de Domiciliar - PNAD2009. http://www.ibge.gov.br/home/estatistica/ populacao/trabalhoerendimento/pnad2009/de fault.shtm (accessed on 11/Oct/2011).

20. Barros MA, César CG, Carandina L, Torre GD. Social inequalities in the prevalence of chronic diseases in Brazil, PNAD-2003. Ciênc Saúde Coletiva 2006; 11:911-26.

21. Cesarino CB, Cipullo JP, Martin JFV, Ciorlia LA, Godoy MRP, Cordeiro JA, et al. Prevalência e fatores sociodemográficos em hipertensos de São José do Rio Preto. Arq Bras Cardiol 2008; 91:31-5.
22. Rosário TM, Scala LCNS, França GVA, Pereira MRG, Jardim PCBV. Prevalência, controle e tratamento da hipertensão arterial sistêmica em Nobres, MT. Arq Bras Cardiol 2009; 93:672-8.

23. Coutinho AP, Ribeiro AB, Neuman AIC. Fatores de risco para doenças crônicas. http:FTP.cve.saude. sp.gov.br/doc (accessed on 28/Aug/2006).

24. Williams B. The year in hypertension. J Am Coll Cardiol 2010; 55:66-73.

25. Coelho LGV, Barua RL, Quigley EM. Latin-american consensus conference on helicobacter pylori infection. Latin-American National Gastroenterological Societies affiliated with the Inter-American Association of Gastroenterolgy (AIGE). Am J Gastroenterol 2000; 95:2688-91.

26. Coelho L. Ulcera péptica gastroduodenal. Rio de Janeiro: Editora Guanabara Koogan; 1998.

27. Coelho LGV. H. pylori e doenças gastroduodenais. 2a Ed. São Paulo: Lemos Editorial e Gráfica; 2002.

28. Oliveira SS, Santos IS, Silva JF, Machado EC. Prevalence of dyspepsia and associated sociodemographic factors. Rev Saúde Pública 2006; 40:420-7.

29. Nascimento OA, Camelier A, Rosa FW, Menezes AM, Perez-Padilla R, Jardim JR. Chronic obstructive pulmonary disease is underdiagnosed and undertreated in São Paulo (Brazil): results of the PLATINO study. Braz J Med Biol Res 2007; 7: 887-95.

30. Franco LJ. Estudo multicêntrico sobre a prevalência do diabetes mellitus no Brasil. Inf Epidemiol SUS 1992; 1:47-73.

31. Kim SG, Yang SW, Jang AS, Seo JP, Han SW, Yeom $\mathrm{CH}$, et al. Prevalence of diabetes mellitus in the elderly of Namwon Country, South Korean. Korean J Intern Med 2002; 17:180-90.

32. Westert GP, Satariano WA, Schellevis FG, van den Bos GA. Patterns of comorbidity and the use of health services in the dutch population. Eur J Public Health 2001; 11:365-72.

33. Struijs JN, Baan CA, Schellevis FG, Westert GP, van den Bos GA. Comorbidity in patiets with diabetes mellitus: impact on medical health care utilization. BMC Health Serv Res 2006; 6:84.

Submitted on 04/Aug/2010

Final version resubmitted on $02 / \mathrm{Dec} / 2011$

Approved on 14/Dec/2011 